\title{
An Improved Optimal Capacity Ratio Design Method for WSB/HPS System Based on Complementary Characteristics of Wind and Solar
}

\author{
Xiaoju Yin, ${ }^{1,2}$ Fengge Zhang, ${ }^{1}$ Zhenhe $\mathrm{Ju}^{2}$ and Yonggang Jiao ${ }^{1}$ \\ ${ }^{1}$ School of Electrical Engineering, Shenyang University of Technology, Shenyang 110870, China \\ ${ }^{2}$ School of Renewable Energy, Shenyang Institute of Engineering, Shenyang 110136, China \\ Correspondence should be addressed to Xiaoju Yin; lnsolyxj@163.com
}

Received 18 September 2014; Revised 1 December 2014; Accepted 7 December 2014

Academic Editor: Peng Shi

Copyright (C) 2015 Xiaoju Yin et al. This is an open access article distributed under the Creative Commons Attribution License, which permits unrestricted use, distribution, and reproduction in any medium, provided the original work is properly cited.

\begin{abstract}
The reliability and economic value of wind and solar power generation system with energy storage are decided by the balance of capacity distribution. The improved capacity balance matching method is proposed in this paper, which not only utilizes the complementary characteristics of the wind and solar power generation system sufficiently but also reduces the charge and discharge times of the battery. Therefore, the generation reliability is improved and the working lifetime of the whole system is lengthened. Consequently, the investment of the battery energy storage is reduced as well as the whole cost is decreased. The experimental result was presented to verify the effectiveness of the improved optimal capacity ratio design method.
\end{abstract}

\section{Introduction}

Separate photovoltaic or wind power generation can achieve a major output fluctuation due to random and intermittent wind/solar resources and needs prodigious battery volume to satisfy load. Actually, the photovoltaic and wind power generation have commendable complementary characteristics in time distribution. The solar energy is adequate and the wind is weak in daytime, while the solar is weak and the wind is strengthened due to the earth's surface difference in temperature at night. In summer, the solar is strong but wind is weak, while the wind is strong but the solar is weak in winter. Taking full advantage of the complementary characteristics of wind and solar can achieve a high power supply reliably, while it can reduce the total cost of the system in the meantime [1].

There are many optimal design methods target-based for stand-alone WSB hybrid power system. The restraint conditions mainly include power supply reliability, total cost of system, and environmental protection. Actually, the traditional optimal design method considers less restraint conditions which include current, frequency, rate in charge/discharge cycles of the battery, and system backup capacity. Moreover, the complementary characteristics of wind and solar resources are not considered a restraint condition [2-8]. Therefore, this paper proposed an improved optimal design method for stand-alone wind-solar-battery hybrid power system. First, the paper formulated WSB/HPS optimal sizing principle. Then, an optimal sizing mode was established and an optimal ratio strategy was proposed. Finally, an average power of $100 \mathrm{~kW}$ system for an example is taken to simulate and verify the improved optimal design method for standalone wind-solar-battery hybrid power system.

\section{Preliminaries}

2.1. Structure and Working Principle of Wind Turbine. Wind turbines consist of wind turbine and generator [9]. In the small wind generator, wind power working process is shown in Figure 1. The kinetic energy of airflow on the wind wheel is converted to mechanical energy by the aerodynamic rife wheel rotation which promotes the wind wheel spin. Since small wind turbine power agencies do not consume energy usually, therefore, the wind turbine generators are 


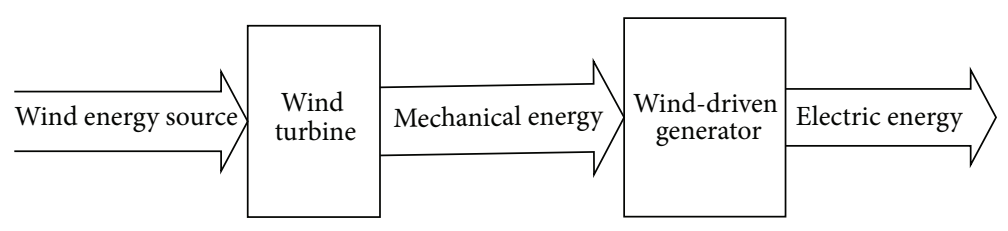

FIGURE 1: Wind power generation process.

driven directly. Eventually, the derived mechanical energy is transformed into electrical energy to supply for the load.

Wind energy is the kinetic energy of the air and therefore is determined by the wind speed and air density, which is given by the following equation:

$$
E=\frac{m v^{2}}{2}
$$

where $E$ is the kinetic energy of air, $m$ is the quality of the object, and $v$ is the movement speed of the object.

Obviously, the above equation can be written as

$$
E=\frac{(\rho v A) v^{2}}{2}=\frac{\rho A v^{3}}{2}
$$

where $\rho$ is the air density and $A$ is the wind swept area.

Since all the energy of air almost is composed of the kinetic energy, therefore, the above equation is expressed by the power form:

$$
P=\frac{\rho A v^{3}}{2}
$$

In fact, all of the wind turbines are not able to convert wind energy into mechanical energy, so the actual power of the wind wheel is

$$
P=0.5 \rho v^{3} A C_{p}
$$

where $C_{p}$ is wind energy utilization factor, whose theoretical maximum is 0.593 . That is, the maximum power obtained can be $59.3 \%$ of the wind energy of the swept area range.

As is well known, wind power requires $\mathrm{AC}$ to $\mathrm{DC}$ rectifier section. In the rectification process, the full bridge rectifier technology of uncontrollable diode is employed in small power generation systems. Since the performance characteristics of a large loss are not obvious, its low cost is considered in this paper without affecting the power generation efficiency.

Figure 2 is a waveform diagram of the output voltage of the rectifier front of wind turbines. It will output stable DC voltage after the full-bridge rectifier filters.

\subsection{The Working Principle and Characteristics of Solar Mod-} ules. First, the power generation principle and equivalent circuit components of solar modules are introduced.

The physical mechanism of the solar module is very similar to the classic PN junction diode. The solar module can use the photovoltaic effect to convert solar energy into electrical energy, and its power generation principle is shown in Figure 3. When solar module receives solar radiation, PN junction carriers will generate an electromotive force gradient that is accelerated in electric field. Once there is a load access, the circuit will occur. The unabsorbed photons will cause the battery temperature and thus emit into the environment.

Under standard illumination conditions, the rated output voltage is $0.48 \mathrm{~V}$. So multiple solar cells need to be connected together to obtain a higher output voltage and a large power capacity. Figure 3 is an equivalent circuit of solar modules.

When the lighting conditions are unchanged, photocurrent $I_{\mathrm{ph}}$ is a constant. It can be considered a constant current source. Output current $I$ is equal to the photocurrent $I_{\mathrm{ph}}$ minus the diode current $I_{d}$ and the leakage current $I_{\text {sh }}$ is derived. The series resistance $R_{s}$ of the current source resistance is determined by the PN junction depth, contact resistance, and impurity.

The diode current is given by the classical diode current expression:

$$
I_{d}=I_{0}\left\{\exp \left[\frac{q\left(V+I R_{s}\right)}{A K T}\right]-1\right\}
$$

where $q=1.6 \times 10^{-19} \mathrm{C}$ is the electronic charge, $K=1.38 \times$ $10^{-23} \mathrm{~J} / \mathrm{K}$ is Boltzmann's constant, $I_{0}$ is the reverse saturation current of diode, $A$ is the ideality factor of $\mathrm{PN}$ junction, and $T$ is the absolute temperature.

Therefore, the output-side current is

$$
I=I_{\mathrm{ph}}-I_{0}\left\{\exp \left[\frac{q\left(V+I R_{s}\right)}{A K T}-1\right]\right\}-\frac{V+I R_{s}}{R_{\mathrm{sh}}} .
$$

In the actual solar cells, the leakage current is very small and is therefore usually negligible.

In the following, the operating characteristics of solar modules are introduced.

Based on the above derivation of the mathematical model of solar modules, the photovoltaic cells model is set up using the Matlab Simulink modeling modules as shown in Figure 4.

According to the simulation model, the solar cell output characteristic curve is plotted where the light intensity is different (the outside temperature is $25^{\circ} \mathrm{C}$ ), as is shown in Figure 5. It can be seen from the figure that the output power of solar modules with an output voltage $U$ and current $I$ is nonlinear and there is a unique point of maximum power output. Our system is designed to track the position of the maximum power point of the solar module to keep the maximum output power, whose aim is to increase the utilization of solar energy.

For the establishment of a stable and balanced voltage to achieve full time power supply system, the energy storage 


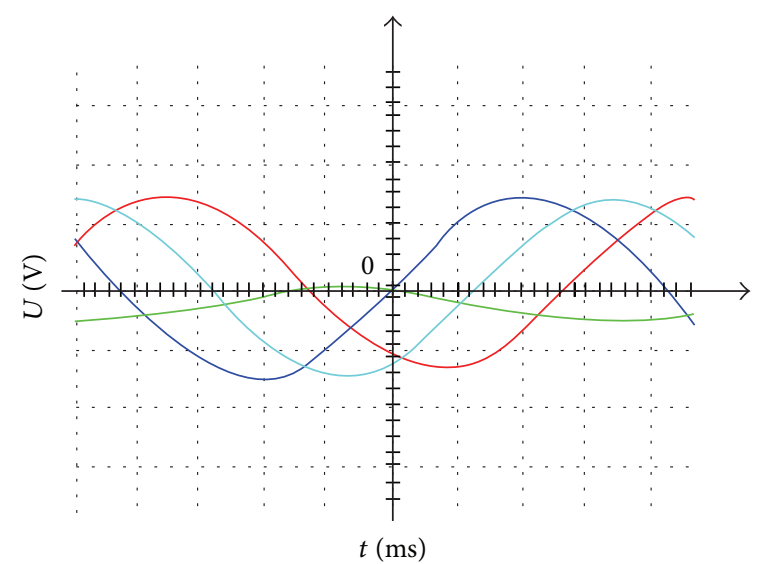

(a)

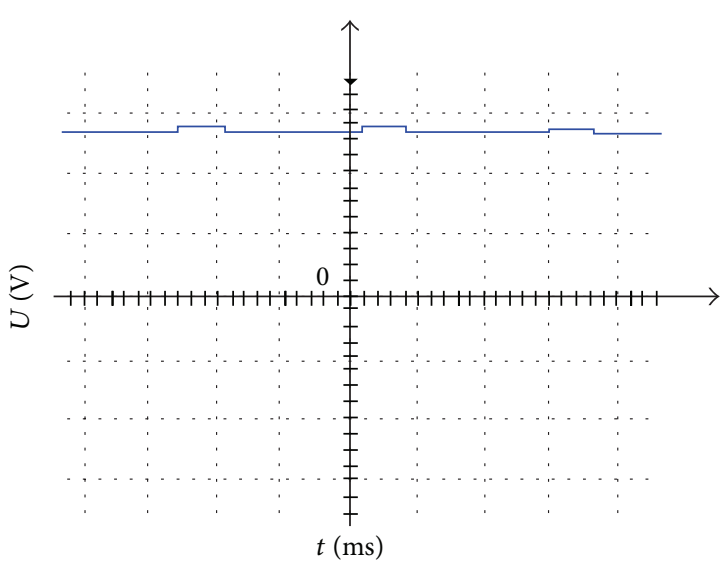

(b)

FIGURE 2: Generated voltage curve of wind turbine. (a) Three-phase alternating current generated by the wind power generator. (b) The full-bridge rectifier filtered voltage waveform.

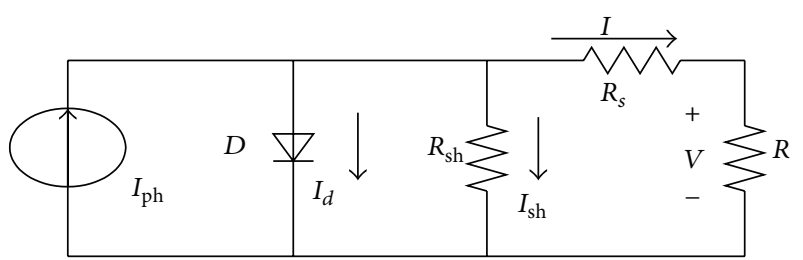

FIGURE 3: Solar photovoltaic battery equivalent circuit.

units must be included in the configuration around wind turbine, solar modules, and load. That is, they attend to store power of wind turbines and solar modules and supply stable power to the load. In practical engineering, as the most economical and convenient storage methods, leadacid batteries are widely used in small and medium sized wind and solar power generation system. Hybrid energy storage system structure is shown in Figure 6. In wind and solar power generation system, the controller is switched on and off to control the super capacitors and batteries charge and discharge strategy, to maximize the advantages of the above two storage forms, and to improve the stability and performance of the power storage unit in the system.

\section{Capacity Optimization Ratio Principles for WSB/HPS System}

In the considered WSB/HPS system, the photovoltaic power generation, wind power generation, and battery assemble are placed on DC bus. The structure of the stand-alone WSB/HPS is proposed in Figure 6.

When the efficiency of wind power and photovoltaic output is low, the batteries are in the course of discharging. Then, the system power relationship is given as

$$
P_{L}(t)=P_{G}(t)+P_{\mathrm{pv}}(t)+P_{\mathrm{bdch}}(t),
$$

where $P_{G}(t)$ and $P_{\mathrm{pv}}(t)$ are photovoltaic and wind power generation unit output, respectively, $P_{\mathrm{bdch}}(t)$ is battery discharging power, and $P_{L}(t)$ is load power. If the system could not satisfy load power supply, a part of load must be switched off or backup power source must be launched. When photovoltaic and wind power are sufficient for load, the batteries are charged by redundant power. So the power relation is given by

$$
P_{L}(t)=P_{G}(t)+P_{\mathrm{pv}}(t)-P_{\mathrm{bdch}}(t) .
$$

If the battery is fully charged, there is excess power and then the solar and wind power quit MPPT operation. It can be seen from (7) and (8) that the considered WSB/HPS system can make the best complementary characteristics by optimizing wind/PV capacity ratio and reduce the capacity and depth of discharge and charge/discharge cycles of the battery. In summary, the optimization target of WSB/HPS includes a high power supply reliability and minimum cost by taking full advantage of complementary characteristics of wind and solar.

\section{Capacity Optimization Ratio Model}

The reliability loss of power supply probability (LPSP) signifies the reliability level of power supply, which is defined as

$$
f_{\text {LPSP }}=\frac{\sum_{i=1}^{N}\left[P_{L}\left(t_{i}\right)-\left(P_{G}\left(t_{i}\right)+P_{\mathrm{pv}}\left(t_{i}\right)+P_{\mathrm{bdch}}\left(t_{i}\right)\right)\right]}{\sum_{i=1}^{N} P_{L}\left(t_{i}\right)},
$$

where $P_{\mathrm{pv}}\left(t_{i}\right), P_{G}\left(t_{i}\right), P_{\mathrm{bdch}}\left(t_{i}\right)$, and $P_{L}\left(t_{i}\right)$ are $\mathrm{PV}$, wind, battery, and load power at " $t_{i}$ " time, respectively. $N$ is the number of sampling interval points. Obviously, the less the $f_{\text {LPSP }}$, the higher the power supply reliability [4]. The summation of photovoltaic and wind generation output power is relative to load power fluctuation. $D_{L}$ signifies the complementary characteristics of solar and wind generation, which is defined as

$$
D_{L}=\frac{1}{\bar{P}} \sqrt{\frac{1}{N} \sum_{i=1}^{N}\left(P_{G}\left(t_{i}\right)+P_{\mathrm{pv}}\left(t_{i}\right)-P_{L}\left(t_{i}\right)\right)^{2}},
$$




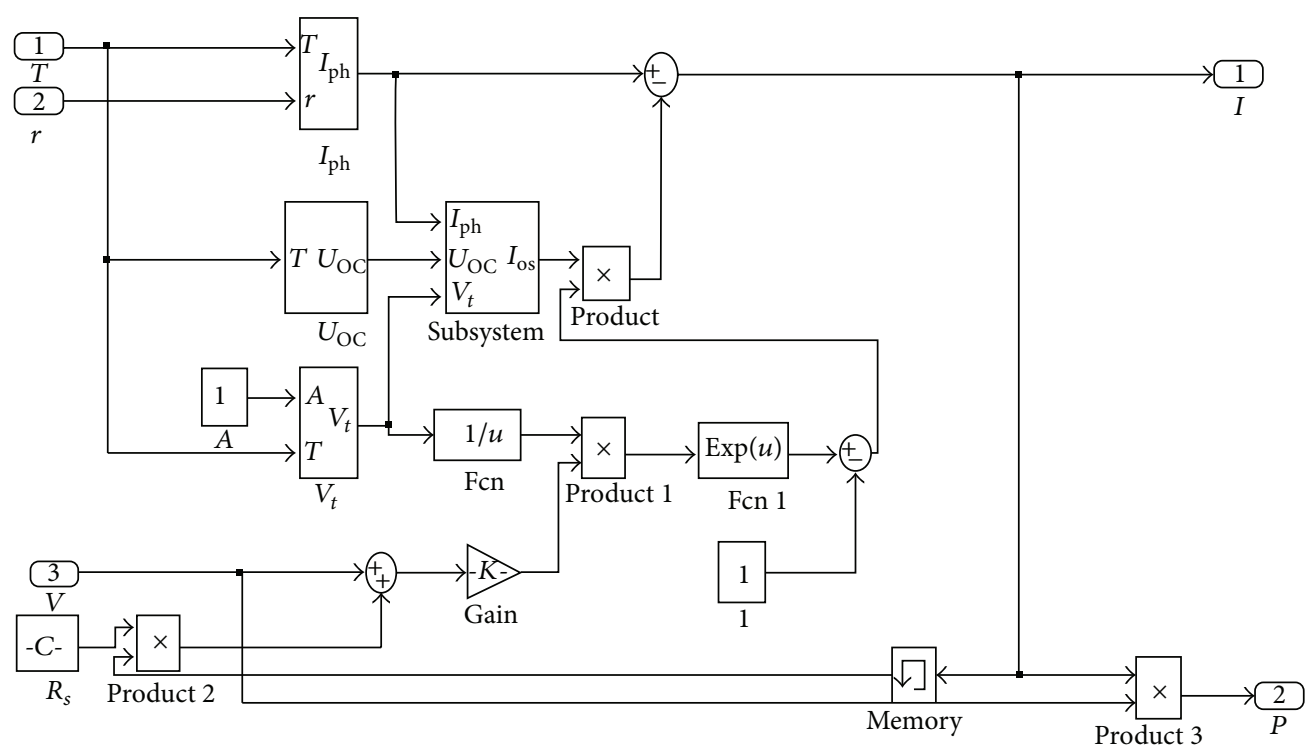

FIGURE 4: The photovoltaic cell model based on Simulink.

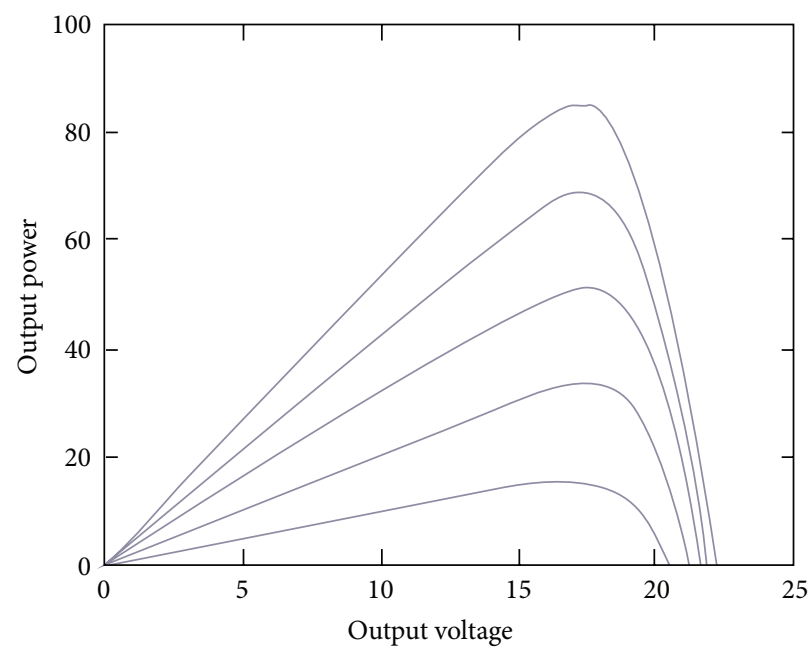

(a)

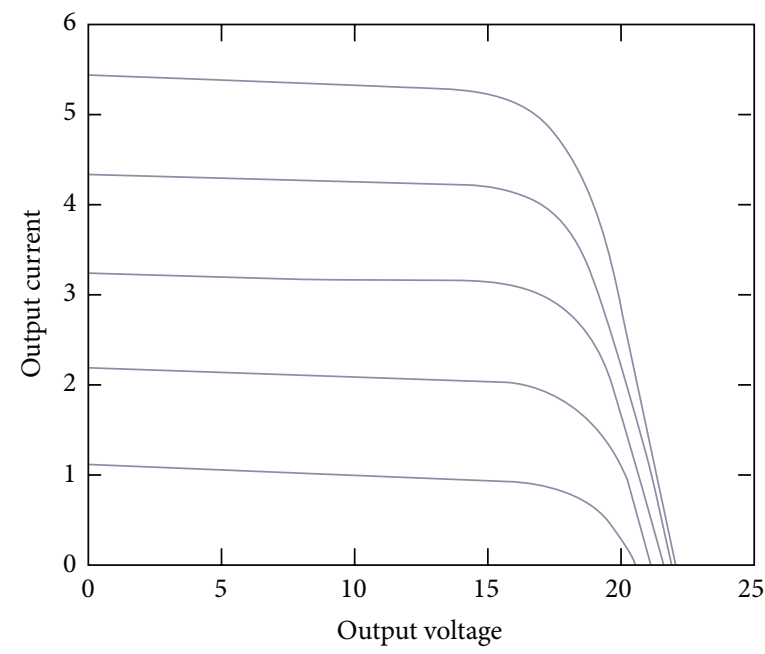

(b)

FIGURE 5: The output characteristic curve of solar cell under different light intensity. (a) Solar cell $P-V$ characteristic curves. (b) Solar cell $I-V$ characteristic curves.

where $\bar{P}$ is the average load power. Obviously, the $D_{L}$ is less when the curve of the complementary characteristics of solar and wind generation is nearer to load power curve. Meantime, the capacity and depth of discharge and charge/ discharge cycles of battery are reduced [5]. Therefore, the complementary characteristics of solar/wind generation are better. Initial investment cost of distributed generator (DG) is presented as

$$
C_{C}=\left(N_{\mathrm{pv}} C_{\mathrm{pv}}+N_{G} C_{G}+N_{b} C_{b}\right) f_{c r},
$$

where $C_{\mathrm{pv}}, C_{G}$, and $C_{b}$ are photovoltaic panel unit-price, wind turbine unit-price, and battery unit-price, respectively. $N_{\mathrm{pv}}, N_{G}$, and $N_{b}$ are the number of photovoltaic panels, the number of wind turbines, and the number of batteries, respectively. $f_{c r}$ is depreciation coefficient, which is defined as

$$
f_{c r}=\frac{r(1+r)^{L_{f}}}{(1+r)^{L_{f}}-1},
$$

where " $r$ " is the depreciation rate; $L_{f}$ is the project life time. Then, the operation and maintenance costs of the considered WSB/HPS system are presented as

$$
C_{\mathrm{OM}}=\sum\left(C_{\mathrm{pv}}^{\mathrm{OM}} t_{\mathrm{pv}}+C_{G}^{\mathrm{OM}} t_{G}+C_{b}^{\mathrm{OM}} t_{b}\right),
$$

where $C_{\mathrm{pv}}^{\mathrm{OM}}, C_{G}^{\mathrm{OM}}$, and $C_{b}^{\mathrm{OM}}$ are $\mathrm{PV}$ power, wind power, battery charge and discharge operation, and maintenance costs under unit time, respectively. $t_{\mathrm{pv}}, t_{G}$, and $t_{b}$ are the running 


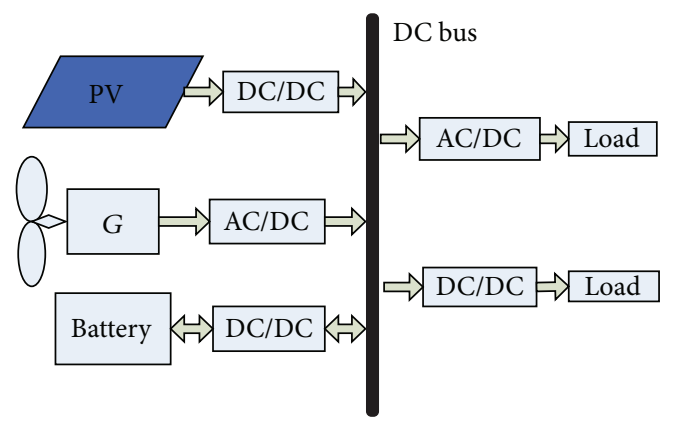

FIGURE 6: Structure of the stand-alone WSBHPS.

time of photovoltaic cells, wind generation unit, and battery unit, respectively. The replacement cost of unit DG and the total cost of WSB-HPS system are given by

$$
\begin{aligned}
& C_{R}=C_{\mathrm{pv}}^{R}+C_{G}^{R}+C_{b}^{R}, \\
& C_{A}=C_{C}+C_{\mathrm{OM}}+C_{R},
\end{aligned}
$$

where $C_{\mathrm{pv}}^{R}, C_{G}^{R}$, and $C_{b}^{R}$ are the number of photovoltaic panels, wind turbines, and batteries, respectively.

The following constraint conditions are considered in this paper.

4.1. DG Unit Quantity Constraint. DG unit installation ground area is regarded as maximum installed capacity constraint. In general, the distance between two adjacent wind generators is 6-10 times of diameter length in the prevailing wind direction. Being perpendicular to the prevailing wind direction, the distance is 3-5 times of diameter length. Meanwhile, the line distance is 8 times of diameter length and column distance is 4 times of diameter length. Therefore, the quantity of wind generators should satisfy (15) and the quantity of installation PV and battery should satisfy (16) and (17):

$$
\begin{gathered}
N_{G} \leq\left[\frac{L}{8 d}+1\right] \cdot\left[\frac{W}{4 d}+1\right], \\
N_{\mathrm{pv}} \leq\left[\frac{S}{S_{\mathrm{pv}}}\right] a_{\mathrm{pv}}, \\
N_{b} \leq\left[\frac{S}{S_{b}}\right],
\end{gathered}
$$

where $S_{\mathrm{pv}}$ and $S_{b}$ are PV and battery area, respectively, and $a_{\mathrm{pv}}$ is shading coefficient.

4.2. DG Unit Minimum Power Constraint. Considering that the photovoltaic generation power output is zero at night, wind generation provides power supply for load. So wind generation should provide average load power at least. In the same way, if wind source is insufficient at daytime, photovoltaic generation should also provide average load power at least. If both the light and wind sources are insufficient, battery must provide load power. Then, an assumption is given below. The battery should ensure that the number of load sustaining running days is $\lambda$. Therefore, the minimum quantity of wind, $\mathrm{PV}$, and battery unit installation must satisfy the following equation:

$$
\begin{gathered}
N_{G} \geq \frac{\overline{P_{\mathrm{Ld}}}}{P_{\mathrm{G}}} \\
N_{\mathrm{pv}} \geq \frac{\overline{P_{\mathrm{Ld}}}}{P_{\mathrm{pv}}} \\
N_{b} \geq \frac{\lambda W_{\mathrm{Ld}}}{\eta C_{b} U_{b} D_{\mathrm{OD} \max }},
\end{gathered}
$$

where $\overline{P_{\mathrm{Ld}}}$ is daily average load power and $P_{\mathrm{G}}$ and $P_{\mathrm{pv}}$ are each wind generator and each photovoltaic output power, respectively. $W_{\mathrm{Ld}}$ is daily load capacity $(\mathrm{kW} \cdot \mathrm{h}) . C_{b}$ and $U_{b}$ are capacity and voltage of unit battery, respectively. $D_{\mathrm{OD} \max }$ is maximum depth of discharge. $\eta$ is battery discharge ratio.

4.3. System Backup Capacity Constraint. Taking the increasing load or faulty units in the system into account, it is necessary that there is enough backup capacity in this system. Consequently, the overall maximum output power of DG units must ensure that there is incremental $m \%$ of load supply power. That is, the following inequality should be satisfied:

$$
\sum P_{k} \geq(1+m \%) P_{L}
$$

where $k$ denotes photovoltaic wind and/or battery unit.

4.4. Battery Charge/Discharge Constraint. This paper established the mathematical representation of battery based on a class of dynamic charge/discharge models named KiBaM model. This model can forecast battery capacity and port realtime voltage. Taking battery lifetime into consideration, the charge/discharge course of battery could be strictly restricted. The state of charge should satisfy (20). The charge ratio $r_{\mathrm{ch}}$ and discharge ratio $r_{\mathrm{dch}}$ should satisfy (21), where $r_{\mathrm{ch} \_}$and $r_{\mathrm{dh} \_R}$ are setpoints. The charge/discharge currents of batteries $I_{\mathrm{ch}}$ and $I_{\mathrm{dh}}$ cannot exceed their corresponding maximum values $I_{\text {chmax }}$ and $I_{\mathrm{dhmax}}$; that is, (22) should be satisfied. The charge/discharge power of battery $\left(P_{\mathrm{bch}}\right.$ and $\left.P_{\mathrm{bdch}}\right)$ should satisfy (23), where the value of $P_{\mathrm{bchmax}}$ and $P_{\mathrm{bdchmax}}$ can be achieved based on KiBaM model:

$$
\begin{gathered}
S_{\mathrm{OC} \min } \leq S_{\mathrm{OC}} \leq S_{\mathrm{OC} \max }, \\
r_{\text {ch }} \leq r_{\text {ch_R }}, \quad r_{\mathrm{dh}} \leq r_{\mathrm{dh} \_R}, \\
I_{\mathrm{ch}} \leq I_{\text {chmax }}, \quad I_{\mathrm{dh}} \leq I_{\text {dhmax }}, \\
0 \leq P_{\text {bch }} \leq P_{\text {bchmax }}, \\
0 \leq P_{\text {bdch }} \leq P_{\text {bdchmax }} .
\end{gathered}
$$

4.5. Battery Charge/Discharge Frequency Constraint. As it is well known, the charge/discharge frequency influences battery's lifetime prodigiously. Therefore, the charge/discharge 


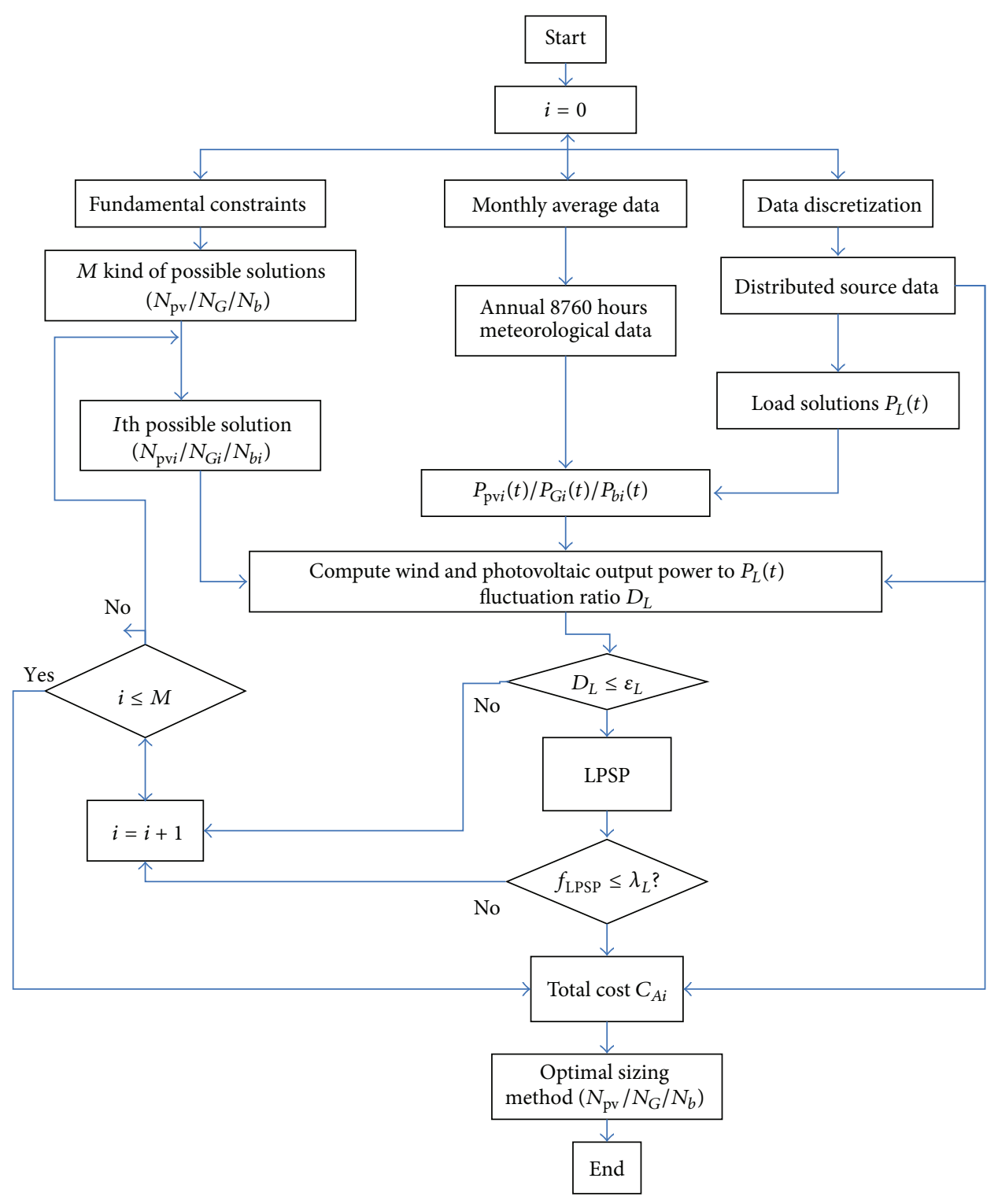

Figure 7: Program flow diagram of the optimal configuration.

times and depth of discharge should be limited. The constraint of discharge depth is determined by (20). In a scheduling period, the times of battery charge and discharge cycle $N_{C}$ should not exceed the limit value $N_{C \max }$. The value of $N_{C \max }$ is integratally decided by the load prediction, the importance of the load, and the battery life and role in the running system. That is, (24) should be satisfied. Since the scheduling period, $S_{\mathrm{OC}}$, may be different, it is difficult to quantify the number of charge and discharge cycles of battery. This paper utilizes the equivalent number of charge/discharge cycles and life curve of battery to calculate the value of $N_{C}$,

$$
N_{C} \leq N_{C \max }
$$

4.6. Power Supply Reliability Constraints. As mentioned above, the reliability loss of power supply probability (LPSP) $f_{\text {LPSP }}$ signifies power supply reliability. Typically, the load power shortage should be in an acceptable range; that is, $\lambda_{L}$ is permissible in the following inequality:

$$
f_{\text {LPSP }} \leq \lambda_{L}
$$

4.7. Complementary Characteristics of Photovoltaic and Wind Power Generator Constraints. To make full use of wind and solar characteristics of the system, the index $D_{L}$ must be less than the reference value $\varepsilon_{L}$,

$$
D_{L} \leq \varepsilon_{L}
$$

\section{Independent Runtime Optimization Strategy for WSB/HPS System}

The total minimum cost of the considered WSB/HPS is chosen as optimization objective function in this paper. The 

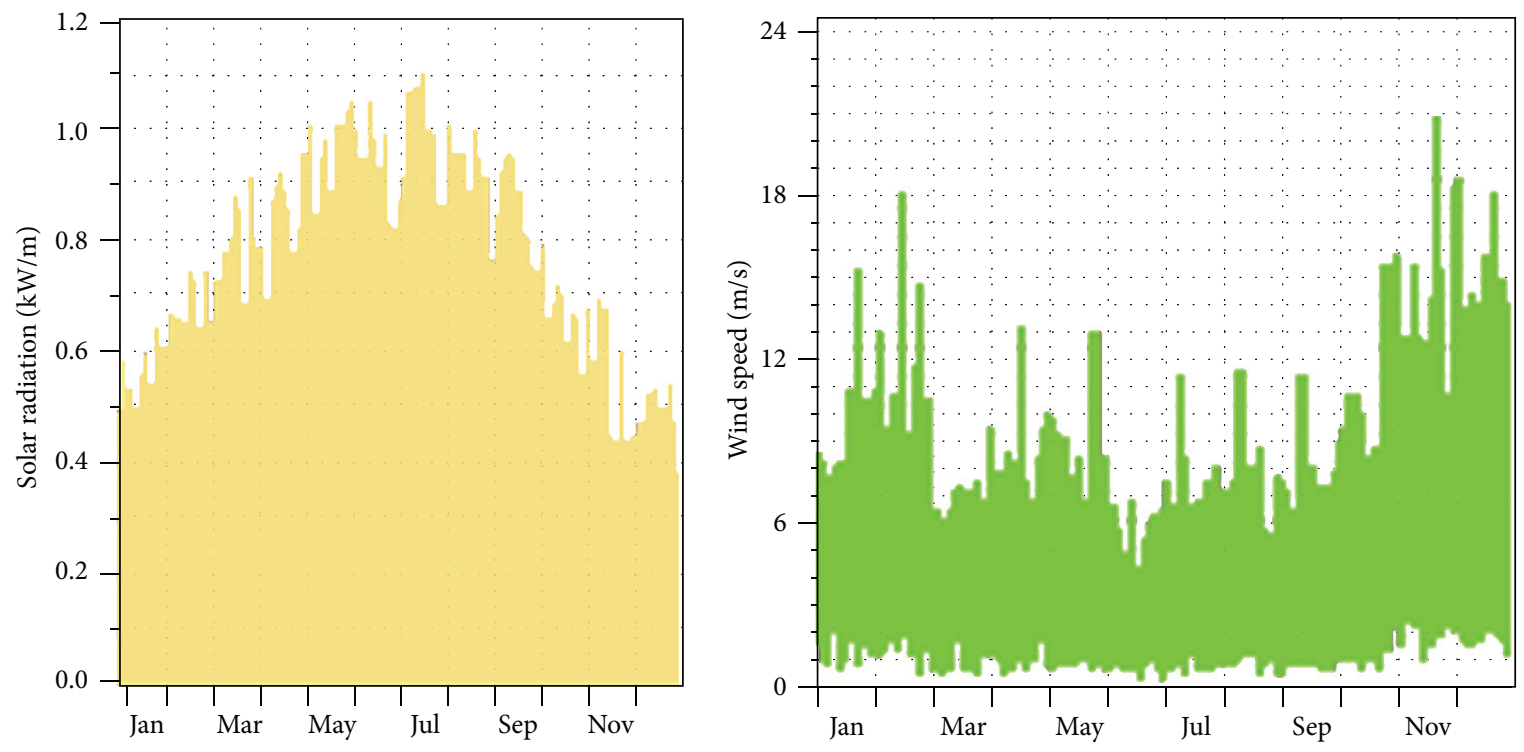

FIgURE 8: The PV Illumination curve and wind speed curve.

relevant expression is presented in (27). The corresponding constraint conditions are given by (15)-(26),

$$
\min f=\min C_{A} .
$$

According to the maximum of DG unit capacity constraints (15)-(17) and the minimum of DG unit power constraint (18), the ranges of $N_{G}, N_{\mathrm{pv}}$, and $N_{b}$ can be determined. Then, considering the system backup capacity constraint (15), the various possible capacity ratios of wind/photovoltaic/battery can be determined. According to wind/photovoltaic/battery output models (12), (13), and (15) and the battery charge and discharge constraints (20)-(24), the output power of wind power, photovoltaic, and battery can be calculated. Consequently, the values of $f_{\text {LPSP }}$ and $D_{L}$ could be figured out. An improved optimization scheme of wind/solar/battery capacity ratio is proposed under the reliability constraint (25) and the complementary characteristics constraint (26). A program flow diagram of the optimal configuration is proposed as shown in Figure 7.

\section{Example Analysis}

6.1. The Example and Calculations. In order to verify that the proposed WSB-HPS capacity ratio optimization design method is reasonable and predominant, this paper presents an example to illustrate how to design an optimal capacity ratio for WSB/HPS system. The simulation software HOMER is employed in this paper $[6,7]$.

The relevant parameters are assumed below. The average power is $100 \mathrm{~kW}$. The peak power is $315 \mathrm{~kW}$. The load rate is $33 \%$. The maximum load utilization hours are $2976 \mathrm{~h}$. The day variation range is $\pm 10 \%$ of the load as WSB-HPS related to the local load. Figure 8 shows the wind speed and the annual light curves which are obtained based on monthly average weather data after discretizing operation. After calculating the annual declination angle of the sun every day, the elevation angle and azimuth of the sun every hour, the corresponding discretizing illumination, and the annual hourly photovoltaic panel radiation are mainly acquired based on empirical formula. The annual discretized meteorological data reflect the basic characteristics of the weather in this example. Taking $100 \mathrm{~kW}$ as the average power of the load, we choose wind turbines of $35 \mathrm{~kW}$ rated power. Taking the PV array port voltage and power levels of the system into account, we choose a kind with single maximum power of $200 \mathrm{~W}$ and corresponding voltage of $24.5 \mathrm{~V}$. When the WSB/HPS system is running, the process of battery charge and discharge is frequent, and therefore, the deep cycle VRLA batteries with monomer capacity of $600 \mathrm{Ah}$ are chosen.

The traditional optimization program can be implemented independently using the HOMER software. The proposed improved optimization program in this paper can realize the calculation of $f_{\text {LPSP }}$ and $C_{A}$ by HOMER software. Consequently, the optimal wind/photovoltaic/battery capacity ratio can be exported to meet all abovementioned constraints. It should be pointed out that the calculation procedure assumes that wind turbines and photovoltaic units are running in MPPT state.

6.2. Optimization Configuration Results for WSB-HPS System. Table 1 shows the comparison of configuration results between the traditional and improved optimization schemes. Figure 9 shows the output power curves of wind power generation and photovoltaic generation. The fluctuation of output power is reduced because a restraint condition that takes full advantage of the complementary characteristics of wind and solar is added. Consequently, fewer batteries are needed in the system, which can ensure power supply reliability and reduce the depth of discharge and charge/discharge cycles to extend lifetime. The cost of whole system slightly rises in that the price of photovoltaic cell panel is higher. 
TABLE 1: Comparison of configuration results between the traditional and improved optimization schemes.

\begin{tabular}{|c|c|c|c|c|}
\hline Optimization scheme & Photovoltaic cell panel & Wind-driven generator & Number of batteries & $\begin{array}{c}\text { Total cost } \\
(\$)\end{array}$ \\
\hline Traditional scheme & 2200 & 10 & 1900 & 1327060 \\
\hline Improved scheme & 2300 & 11 & 1630 & 1336532 \\
\hline Optimization scheme & $\begin{array}{l}\text { Unit power cost } \\
\$ /(\mathrm{kWh})\end{array}$ & \multicolumn{2}{|c|}{$D_{L}$} & $f_{\text {LPSP }}$ \\
\hline Traditional scheme & 0.133 & \multicolumn{2}{|c|}{1.36} & 0.1 \\
\hline Improved scheme & 0.134 & \multicolumn{2}{|c|}{1.25} & 0.09 \\
\hline
\end{tabular}

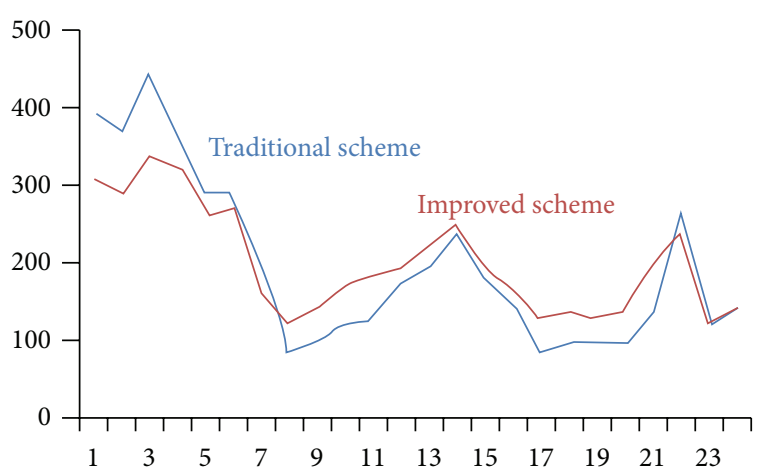

Figure 9: The output power curves of wind power generation and photovoltaic generation.

\section{Conclusions}

An improved optimal capacity ratio design method based on complementary characteristics of wind and solar is proposed in this paper. Under the precondition that the reliability of system is guaranteed, the total minimum cost of the WSB/HPS system is achieved by taking full advantage of wind and solar complementary characteristics. Since all the constraints in the energy conversion process of system are almost proposed in the optimization model, such as the current, depth, and times constraints of battery charge and discharge, the quantity constraint of DG units, and so forth, the yielding optimal results are more accurate and reasonable.

\section{Conflict of Interests}

The authors declare that there is no conflict of interests regarding the publication of this paper.

\section{Acknowledgment}

This work is supported by National Nature Science Foundation of China under Grants 61372195, 61371200, and 61304069.

\section{References}

[1] T. Esram and P. L. Chapman, "Comparison of photovoltaic array maximum power point tracking techniques," IEEE Transactions on Energy Conversion, vol. 22, no. 2, pp. 439-449, 2007.
[2] R. Chedid and S. Rahman, "Unit sizing and control of hybrid wind-solar power systems," IEEE Transactions on Energy Conversion, vol. 12, no. 1, pp. 79-85, 1997.

[3] A. Woyte, V. V. Thong, R. Belmans, and J. Nijs, "Voltage fluctuations on distribution level introduced by photovoltaic systems," IEEE Transactions on Energy Conversion, vol. 21, no. 1, pp. 202-209, 2006.

[4] B. S. Borowy and Z. M. Salameh, "Methodology for optimally sizing the combination of a battery bank and PV array in a Wind/PV hybrid system," IEEE Transactions on Energy Conversion, vol. 11, no. 2, pp. 367-373, 1996.

[5] G. B. Shrestha and L. Goel, "A study on optimal sizing of stand-alone photovoltaic stations," IEEE Transactions on Energy Conversion, vol. 13, no. 4, pp. 373-378, 1998.

[6] P. Lilienthal, T. Lambert, and T. Ferguson, "Hybrid optimization model for electric renewable (HOMER) [EB/OL]," National Renewable Energy Lab (NREL) 2000-02-14 [2010-1108], http://www.nrel.gov/HOMER.

[7] J. H. Aylor, A. Thieme, and B. W. Johnson, "A battery state-ofcharge indicator for electric wheelchairs," IEEE Transactions on Industrial Electronics, vol. 39, no. 5, pp. 398-409, 1992.

[8] V. Mummadi, U. Katsumi, and U. Katsumi, "Feedforward maximum power point tracking of PV systems using fuzzy controller," IEEE Transactions on Aerospace and Electronic Systems, vol. 38, no. 3, pp. 969-981, 2002.

[9] K. H. Chao, C. J. Li, and M. H. Wang, "A maximum power point tracking method based on extension neural network for PV systems," in Advances in Neural Networks-ISNN 2009, vol. 5551 of Lecture Notes in Computer Science, pp. 745-755, Springer, Berlin, Germany, 2009. 


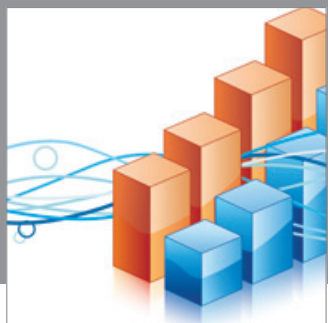

Advances in

Operations Research

mansans

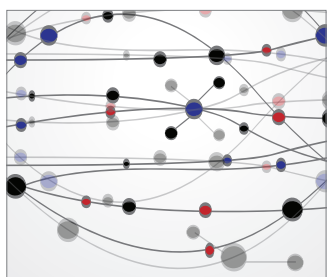

The Scientific World Journal
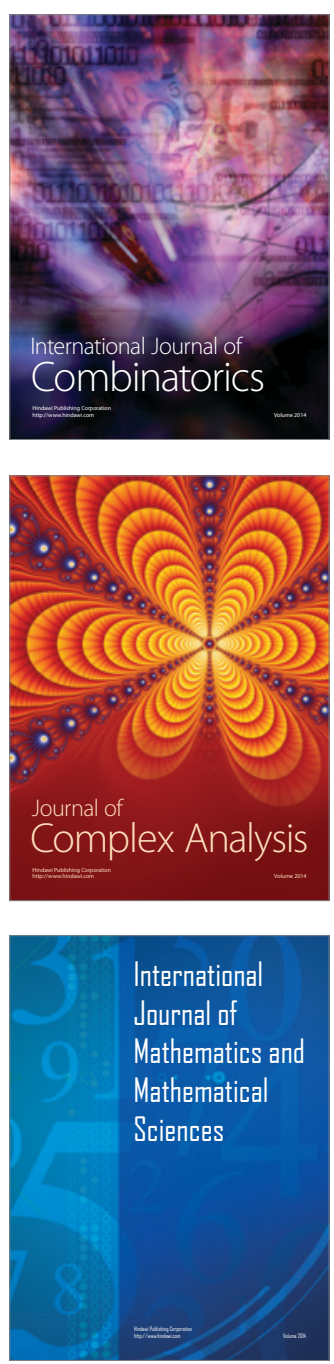
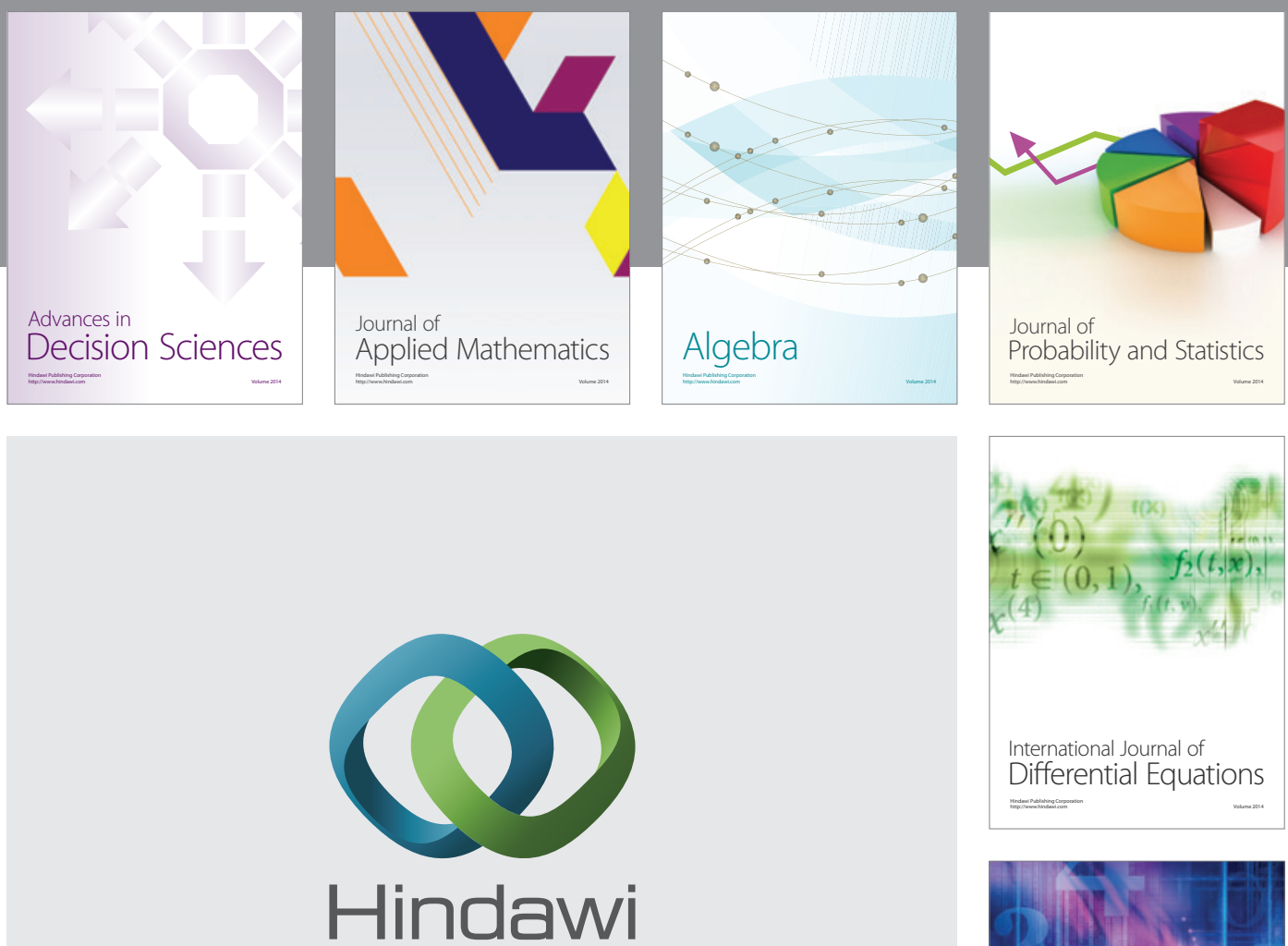

Submit your manuscripts at http://www.hindawi.com
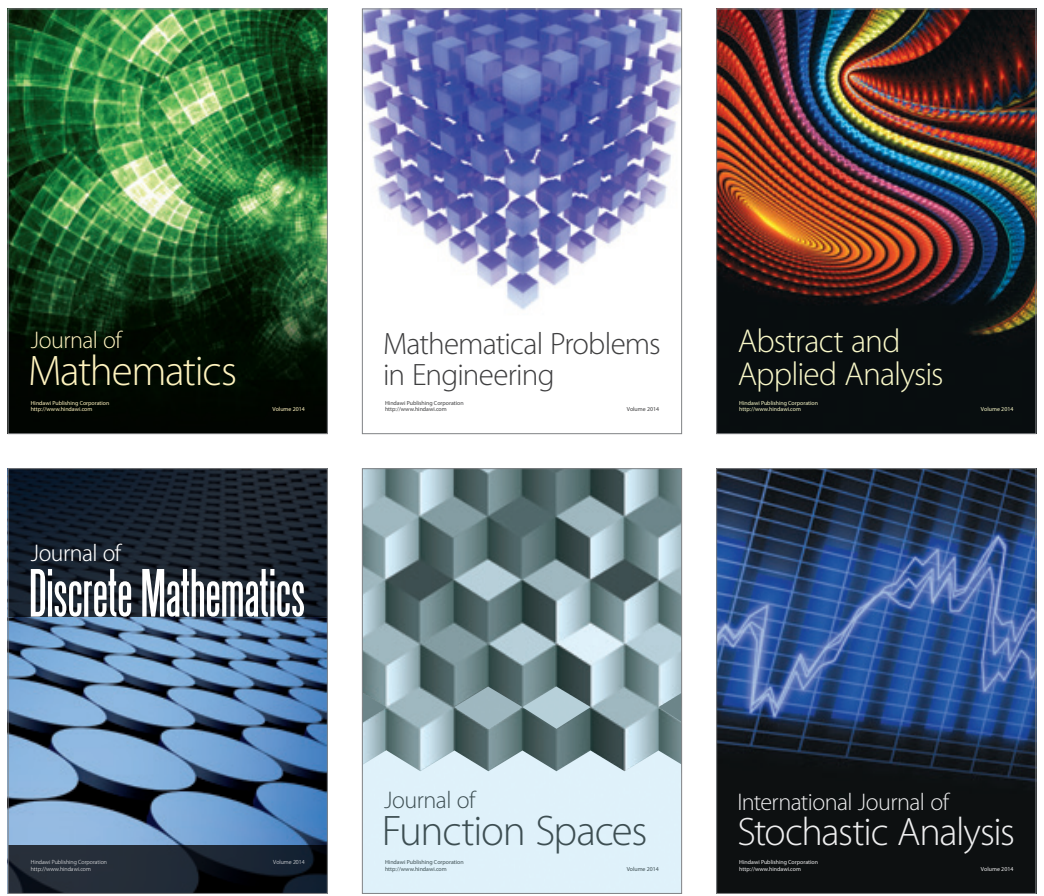

Journal of

Function Spaces

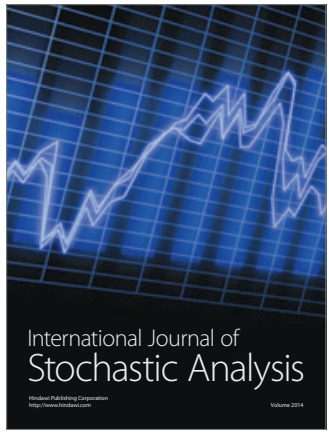

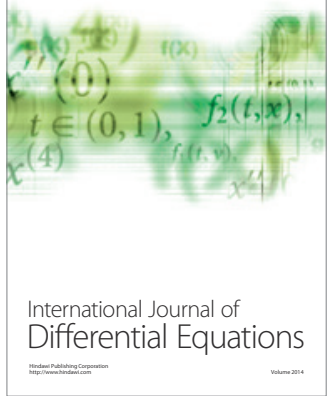
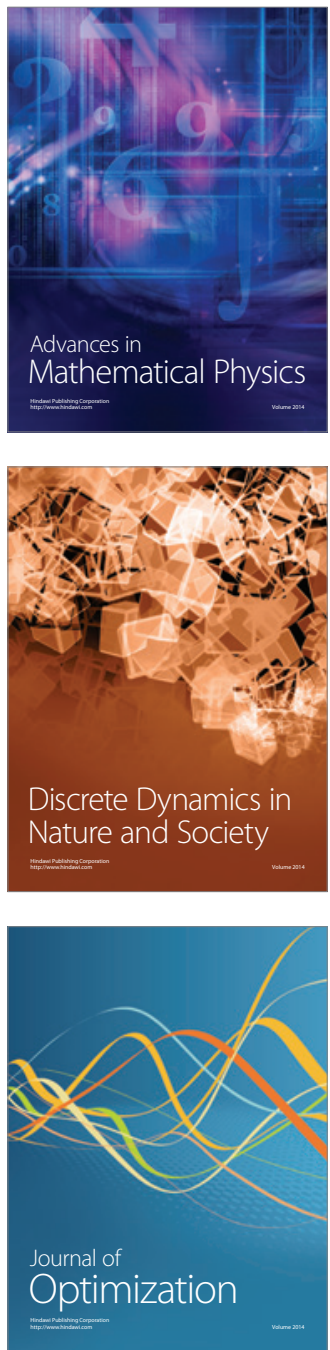